\title{
Emergence of non albicans Candida in a tertiary care hospital of north India
}

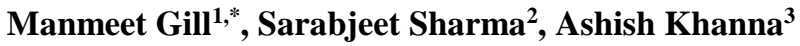 \\ ${ }^{1}$ Associate Professor, ${ }^{2}$ Professor \& HOD, ${ }^{3}$ Professor, Dept. of Microbiology, Sri Guru Ram Das Institute of Medical Sciences and \\ Research, Amritsar, Punjab, India
}

*Corresponding Author:

Email: drmanmeetgill@gmail.com

\begin{abstract}
Introduction: Over past few years, a dramatic increase in the incidence of infections caused by Candida species is seen, which has been attributed to increased number of immunocompromised patients, widespread use of broad spectrum antibiotics, long term use of corticosteroids and immunosuppressive drugs, prolonged hospital stay and use of advanced life support systems

Aims and Objectives: To determine the incidence of Candida infections among patients admitted to a tertiary care teaching hospital of north India, characterise Candida isolates upto to specie level and also to evaluate presence of any drug resistance among these strains.

Material and Methods: Present study was a hospital based prospective study carried out in the Department of Microbiology, of a tertiary care hospital in north India, over a period of one year from June 2016 to May 2017. For all Candida isolates obtained from various clinical samples, identification to the species level and anti-fungal susceptibility testing was done by automated Vitek 2 compact system (Biomerieux). Results were interpreted as per CLSI guidelines.

Results: A shift of trends from Candida albicans to non albicans Candida was observed as out of total 56 isolates, the number of Candida albicans isolates was 16 (28.6\%) and non-albicans Candida was 40 (72.4\%). Anti-fungal susceptibility test results showed high susceptibility to Voriconazole and Amphotericic B. Only 5.35\% (3/56) of Candida isolates showed resistance.

Conclusions: Since non albicans Candida has emerged as an important nosocomial pathogen and these species are intrinsically resistant to some of the commonly used anti fungal drugs so anti-fungal susceptibility should be routinely performed to improve the treatment outcomes, for the benefit of the patient.
\end{abstract}

Keywords: Candida albicans, Shift, non albicans Candida, Anti fungal susceptibility testing.

\section{Introduction}

Candida is a component of commensal flora of human body and at the same time an important nosocomial pathogen, especially in critically ill and immunocompromised patients. ${ }^{1,2}$ Over past few years there has been a dramatic increase in the incidence of infections caused by Candida species making them the fourth leading cause of blood steam infections in USA and sixth among hospital acquired infections. ${ }^{3,4}$ This rise has been attributed to increased number of immunocompromised patients, widespread use of broad spectrum antibiotics, long term use of corticosteroids and immunosuppressive drugs, prolonged hospital stay and use of advanced life support systems. ${ }^{5}$

Contrary to the previous trends where Candida albicans used be predominant specie causing invasive candidiasis, a shift towards non albicans Candida has been observed recently besides association with higher mortality and morbidity. ${ }^{6-8}$ This shift in epidemiology has been linked to increased use of azoles. ${ }^{7,9,10}$

Since Candida can cause opportunistic infections in both immunocompromised as well as immunocompetent persons, we undertook a study to determine the incidence of Candida infections among patients admitted to a tertiary care teaching hospital of north India, to characterise Candida isolates upto to specie level in order to know any shift from Candida albicans to non albicans Candida and also to evaluate presence of any drug resistance among these strains.

\section{Materials and Methods}

Ours was a hospital based prospective study carried out in the Department of Microbiology of a tertiary care hospital in north India over a period of one year from June 2016 to May 2017.

From various clinical samples (Blood, urine, pus, urinary catheter tips, fluids etc) processed in Microbiology lab for routine diagnostic work up, 56 consecutive (non repeat) candida isolates obtained were included in the study. Relevant clinical history was also taken.

The processing of the clinical specimens was done as per standard microbiological techniques. ${ }^{11}$ For blood steam infections, blood culture bottles were incubated in BacT alert 3D system (Biomeriuex) and samples shown positive by the system were subcultured on blood agar and Sabouraud's dextrose agar( SDA).

For other clinical samples also, candida isolates obtained on blood agar culture plates were subcultured on SDA for further processing. The growth obtained on SDA was characterised by colony morphology, Gram staining, Germ tube formation and identification to the species level and anti-fungal susceptibility testing was done by automated Vitek 2 compact system (Biomerieux) as per manufactures instructions, using yeast identification and anti fungal susceptibility cards. Results were interpreted as per CLSI guidelines.

Statistical analysis 
Statistical analysis was done using SPSS version 17.0 software and MS excel 2007.

\section{Results and observation}

In our study candida isolates obtained from 56 cases, that fulfilled the diagnostic criteria for candidiasis, were included and further processed for species identification and anti-fungal susceptibility testing with VITEK 2 Compact system (Biomerieux).

The results showed predominance of males, with male to female ratio is $1.4: 1$

Preponderance of non albicans Candida over Candida albicans was also observed as out of total 56 isolates, the number of Candida albicans isolates was 16 (28.6\%) and non-albicans Candida was 40 (72.4\%).

Among non albicans Candida, Candida tropicalis was the predominant species $27(48.21 \%)$ followed by Candida utilis 9 (16.09\%), Candida gullermondii 2
(3.57\%), Candida parapsilosis 1 (1.78\%), Candida pelliculosa 1 (1.78\%). (Table 1, Fig. 1)

The largest number of candida isolates was obtained from blood cultures (28) followed by urine cultures (14), Foley's catheter tip cultures (13) and others (1). Candida tropicalis was the predominant species among blood and urine cultures isolates whereas Candida albicans was the predominant species in foley catheter tip culture isolates.

Most common predisposing factors were prior antibiotics use in $52(92.85 \%)$ and hospital stay of more than two weeks in $50(89.28 \%)$ cases. Other associated risk factors were indwelling catheter, diabetes, surgery, low birth weight in case of neonates (Table 2, Fig. 2).

Antifungal susceptibility test results showed high susceptibility to Voriconazole and Amphotericic B. Only 5.35\% (3/56) of Candida isolates showed resistance (Table 3).

Table 1: Distribution of Candida isolates obtained from various clinical specimens $(n=56)$

\begin{tabular}{|l|c|c|c|c|c|c|c|}
\hline \multicolumn{1}{|c|}{$\begin{array}{c}\text { Clinical } \\
\text { Specimen }\end{array}$} & $\begin{array}{c}\text { Candida } \\
\text { albicans }\end{array}$ & $\begin{array}{c}\text { Candida } \\
\text { tropicalis }\end{array}$ & $\begin{array}{c}\text { Candida } \\
\text { utilis }\end{array}$ & $\begin{array}{c}\text { Candida } \\
\text { gullermondii }\end{array}$ & $\begin{array}{c}\text { Candida } \\
\text { parapsilosis }\end{array}$ & $\begin{array}{c}\text { Candida } \\
\text { pelliculosa }\end{array}$ & Total \\
\hline Blood & $3(10.7 \%)$ & $\begin{array}{c}14 \\
(50 \%)\end{array}$ & $9(32.14 \%)$ & $\begin{array}{c}1 \\
(3.57 \%)\end{array}$ & 0 & $\begin{array}{c}1 \\
(3.57 \%)\end{array}$ & $\begin{array}{c}28 \\
(50 \%)\end{array}$ \\
\hline Urine & $\begin{array}{c}4 \\
(28.57 \%)\end{array}$ & $\begin{array}{c}10 \\
(71.42 \%)\end{array}$ & 0 & 0 & 0 & 0 & 14 \\
$(25 \%)$
\end{tabular}

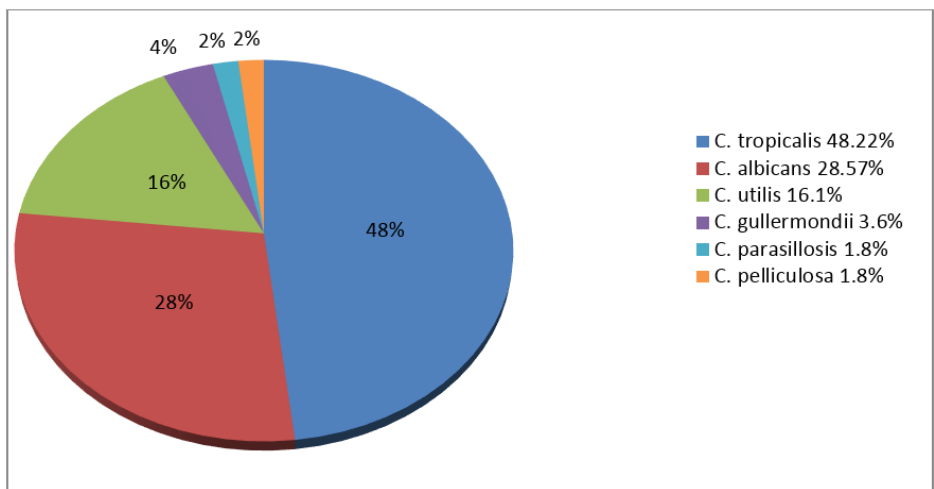

Fig. 1: Specie wise distribution of Candida isolates

Table 2: Predisposing factors (number of patients $n=56$ )

\begin{tabular}{|l|l|}
\hline Predisposing factors & Number of patients \\
\hline Low birth-weight neonates & $13(23.21 \%)$ \\
\hline Age more than 50yrs & $20(35.71 \%)$ \\
\hline Hospital stay $>$ weeks & $50(89.28 \%)$ \\
\hline Prior antibiotic usage & $52(92.85 \%)$ \\
\hline H/O Diabetes mellitus & $5(8.92 \%)$ \\
\hline Prior surgery & $4(7.14 \%)$ \\
\hline Indwelling catheter & $40(71.42 \%)$ \\
\hline
\end{tabular}




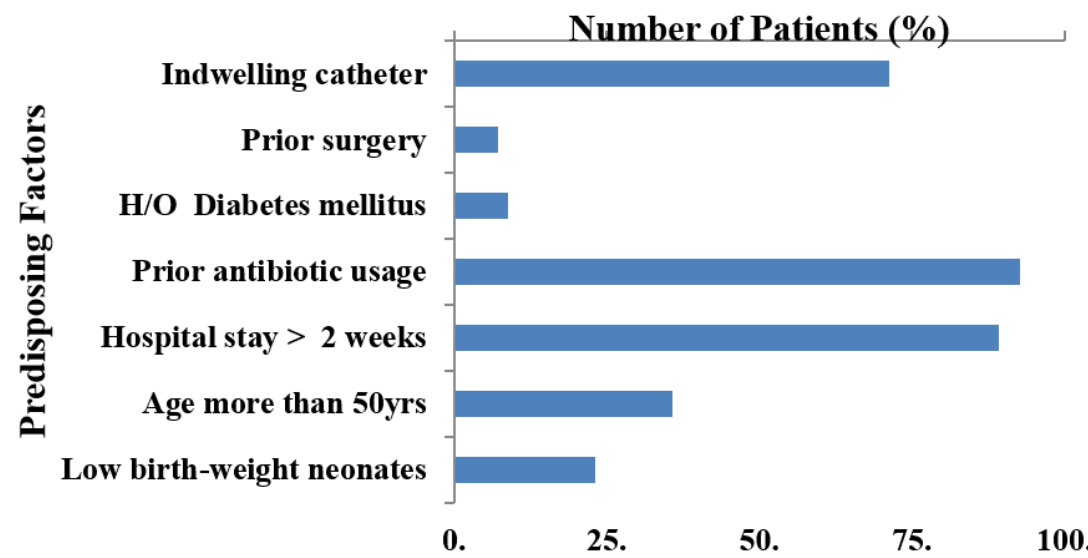

Fig. 2

Table 3: Anti-fungal susceptibility results

\begin{tabular}{|c|c|c|c|c|c|c|c|c|c|c|c|c|}
\hline \multirow[t]{2}{*}{ Candida sp } & \multicolumn{2}{|c|}{ Fluconazole } & \multicolumn{2}{|c|}{ Voriconazole } & \multicolumn{2}{|c|}{ Caspofugin } & \multicolumn{2}{|c|}{ Micafungin } & \multicolumn{2}{|c|}{$\begin{array}{l}\text { Amphoteri- } \\
\text { cin B }\end{array}$} & \multicolumn{2}{|c|}{ Flucytocine } \\
\hline & $\mathrm{S}$ & $\mathrm{R}$ & $\mathrm{S}$ & $\mathrm{R}$ & $\mathrm{S}$ & $\mathrm{R}$ & $\mathrm{S}$ & $\bar{R}$ & $\mathrm{~S}$ & $\overline{\mathrm{R}}$ & $\mathrm{S}$ & $\mathrm{R}$ \\
\hline $\begin{array}{l}\text { C.albicans } \\
\text { (16) }\end{array}$ & $\begin{array}{c}16 \\
(100 \%) \\
\end{array}$ & 0 & $\begin{array}{c}16 \\
(100 \%) \\
\end{array}$ & 0 & $\begin{array}{c}16 \\
(100 \%) \\
\end{array}$ & 0 & $\begin{array}{c}16 \\
(100 \%) \\
\end{array}$ & 0 & $\begin{array}{c}16 \\
(100 \%) \\
\end{array}$ & 0 & $\begin{array}{c}16 \\
(100 \%) \\
\end{array}$ & 0 \\
\hline $\begin{array}{l}\text { C.tropicalis } \\
\text { (27) }\end{array}$ & $\begin{array}{c}25 \\
(96.3 \%)\end{array}$ & $\begin{array}{c}2 \\
(3.7 \%)\end{array}$ & $\begin{array}{c}27 \\
(100 \%)\end{array}$ & 0 & $\begin{array}{c}26 \\
(96.3 \%)\end{array}$ & $\begin{array}{c}1 \\
(3.7 \%)\end{array}$ & $\begin{array}{c}27 \\
(100 \%)\end{array}$ & 0 & $\begin{array}{c}27 \\
(100 \%)\end{array}$ & 0 & $\begin{array}{c}27 \\
(100 \%)\end{array}$ & 0 \\
\hline $\begin{array}{l}\text { C.utilis } \\
\text { (9) }\end{array}$ & $\begin{array}{c}9 \\
(100 \%)\end{array}$ & 0 & $\begin{array}{c}9 \\
(100 \%)\end{array}$ & 0 & $\begin{array}{c}9 \\
(100 \%)\end{array}$ & 0 & $\begin{array}{c}9 \\
(100 \%)\end{array}$ & 0 & $\begin{array}{c}9 \\
(100 \%)\end{array}$ & 0 & $\begin{array}{c}9 \\
(100 \%)\end{array}$ & 0 \\
\hline $\begin{array}{l}\text { C.gullermondii } \\
\text { (2) }\end{array}$ & $\begin{array}{c}2 \\
(100 \%)\end{array}$ & 0 & $\begin{array}{c}2 \\
(100 \%)\end{array}$ & 0 & $\begin{array}{c}2 \\
(100 \%)\end{array}$ & 0 & $\begin{array}{c}2 \\
(100 \%)\end{array}$ & 0 & $\begin{array}{c}2 \\
(100 \%)\end{array}$ & 0 & $\begin{array}{c}2 \\
(100 \%)\end{array}$ & 0 \\
\hline $\begin{array}{l}\text { C.parapsilosis } \\
\text { (1) }\end{array}$ & $\begin{array}{c}1 \\
(100 \%)\end{array}$ & 0 & $\begin{array}{c}1 \\
(100 \%)\end{array}$ & 0 & $\begin{array}{c}1 \\
(100 \%)\end{array}$ & 0 & $\begin{array}{c}1 \\
(100 \%)\end{array}$ & 0 & $\begin{array}{c}1 \\
(100 \%)\end{array}$ & 0 & $\begin{array}{c}1 \\
(100 \%)\end{array}$ & 0 \\
\hline $\begin{array}{l}\text { C.pelliculosis } \\
\text { (1) }\end{array}$ & $\begin{array}{c}1 \\
(100 \%)\end{array}$ & 0 & $\begin{array}{c}1 \\
(100 \%)\end{array}$ & 0 & $\begin{array}{c}1 \\
(100 \%)\end{array}$ & 0 & 1 & 0 & $\begin{array}{c}1 \\
(100 \%)\end{array}$ & 0 & $\begin{array}{c}1 \\
(100 \%)\end{array}$ & 0 \\
\hline
\end{tabular}

\section{Discussion}

The current prospective analytical study over a period of one year reveals preponderance of non albicans Candida over Candida albicans which has been highlighted by similar other studies from different parts of the world. ${ }^{9}, 12,13$

In our study, out of 56 Candida isolates recovered from various clinical specimens, $16(28.6 \%)$ were Candida albicans and 40 (71.4\%) were non albicans Candida which is in concordance with another study by Sachin $C$ et al that also showed higher incidence of non albicans Candida (63.3\%) over Candida albicans $(36.7 \%) .{ }^{14}$ This shift toward non albicans Candida has been attributed to wide spread use of azoles. A study published by Oberoi K Jaswinder et al, they found a statistically significant relation between fluconazole use and increase in the isolation of non albicans species. ${ }^{15}$ However in our study the most common isolated species was Candida tropicalis and it showed $96 \%$ sensitivity to fluconazole. We also observed 9 cases of candidemia due to Candida utilis in newborn patients admitted to NICU over a period of 3 months during this study. All of these were low birth weight premature babies who were critically ill and were on multi drug therapy. Similar cases of candidemia by Candida utilise have been reported by Grlic A L et al and Shivadasan J et al, in neonates. ${ }^{16,17}$

In sample wise distribution of Candida isolates, a predominance of blood isolates seen as follows. Blood isolates $28(50 \%)$, urine isolates $14(25 \%)$, Foley's catheter tip isolates13 (23.21\%) and 1 isolate from drainage fluid (1.7\%). Out of 651 positive blood cultures, 28 (4.3\%) were positive for Candida species. A lot of variation in prevalence of Candidemia has been reported in different parts of India. Xess et al from AIIMS, New Delhi has reported a prevalence rate of $6 \%$ where as another New Delhi based study reported $18 \%$ prevalence rate. ${ }^{18-20}$

Higher number of isolates from blood compared to other samples in our a study may be due to more use of invasive devices or may be because most of the patients were critically ill and were on broad spectrum antibiotic therapy.

It is also observed that the maximum number of Candida isolates were recovered from the patients admitted to different critical care units of the hospital 
(48/56). In these patients, the leading predisposing factors to candida infection was use of broad spectrum antibiotics followed by prolonged hospital stay which has been highlighted by other studies also. ${ }^{21,22}$

In age \& sex distribution, age of the patients ranged from 1 day to 80 years and male to female ratio is 1.4:1, shows predominance of males which is statistically significant $(p>0.05)$. Few other studies have also reported predominance of males over females. ${ }^{7,23}$

Candidal infections are usually treated with azoles and echinocandins as very frequently these isolates are resistant to Amphotericin B or develop resistance while patient is on therapy with Amphotericin B. Therefore a constant vigil is required during treatment besides need for periodic evaluation of anti fungal sensitivity and resistance is needed. Antifungal sensitivity pattern observed in our study shows that only $5.35 \%$ candida isolates are resistant to anti fungal drugs and maximum resistance is seen against Fluconazole (table 3). We also observe that $100 \%$ Candida albicans, isolates are sensitive to Fluconazole and other drugs. Almost similar observations has been reported in a study by Akortha $E E$ et all who also observed high Fluconazole susceptibility of $95.7 \%$ among Candida albicans isolates [24]. Furthermore, all strains of Candida tropicalis the predominant specie isolated in our study were uniformly sensitive to Amphotericin-B (100\%); 2 isolastes (7.4\%) are resistant to Fluconazole and $1(3.7 \%)$ is resistant to Caspofungin. Similar observations reported by Yesudhason BL et al. $^{25}$

\section{Conclusion}

In our study we observed that non albicans Candida has emerged as an important nosocomial pathogen. Since non albicans species are intrinsically resistant to some of the commonly used anti fungal drugs so antifungal susceptibility should be routinely performed to improve the treatment outcomes, for the benefit of the patient.

\section{References}

1. Chander J. Opportunistic mycoses. In: Chander J, editor. Textbook of Medical Mycology. Mehta publishers.3rd ed;2011:266-90.

2. Astekar M, Bhatiya PS, Sowmya G V. Prevalence and characterization of opportunistic candida infections among patients with pulmonary tuberculosis. J Oral Maxillofac Pathol 2016;20:183-9.

3. Nur Y, Ulker U, Yucesoy M, Nedim C, Ayse Y. Nosocomal bloodstream infections associated with Candida species in a Turkish University Hospital, Mycoses 2006;49(2):134-8.

4. Mehta A, Date VS. Determination of incidence of differenct Candida spp. in clinical specimens and characterization of Candida species isolate. Indian J Microbiol Res 2016;3(4):342-51.

5. Nucci M, Marr KA. Emerging fungal disease. Clin Infect Dis 2005; 41:521-26.

6. Jha BK, Dey S, Tamang MD, Joshi ME, Shivananda PG. Characterization of Candida species isolated from cases of lower respiratory tract infection. Kathmandu Uni. Med J. 2006;4(15):290-4.

7. Capoor M, Nair D, Deb M, Verma P, Srivastava L, Aggarwal P. Emergence of Non-albicans Candida species and antifungal resistance in a Tertiary Care Hospital. Jpn, J. Infect. Dis. 2005;58:344-8.

8. Dimopoulos G, Ntziora F, Rachiotis G, Armaganidis, Mathew EF. Candida albicans versus Non-albicans Intensive care unit acquired bloodstream infections: Differences in Risk factors and outcome. Anesth. Analg 2008;106(2):523-9.

9. Agarwal J, Bansal S, Malik GK, Jain Amita. Trends in Neonatal Septicemia: Emergence of Non-albicans Candida, Indian Ped. J. 2004;41:712-15.

10. Magill SS, Shields C, Sears CL, Choti M, Merz WG. Triazole cross-resistance among Candida spp.: case report, occurrence among bloodstream isolates, and implications for antifungal therapy. J Clin Microbiol. 2006;44:529-35.

11. Koneman FW, Allen SD, Janda WM, Wine WC, Schreckenberger PC, Procop GW et al. Koneman's Color Atlas and Textbook of Diagnostic Microbiology. 6th ed. Philadelphia: Lippincott Williams and Wilkins; 2006

12. Jain M, Dogra V, Mishra B et.al. Candiduria in catheterized intensive care unit patients: emerging microbiological trends, IJPM. 2011;54:552-5.

13. Chakrabati A, Singh K and Das S. Changing face of nosocomial Candidemia. Ind Journal of Med Micribiol. 1999; 17:160-6.

14. Sachin C. Deorukhkar, Santosh Saini, and Stephen Mathew, "Non-albicans Candida Infection: An Emerging Threat," Interdisciplinary Perspectives on Infectious Diseases, vol. 2014, Article ID 615958, 7 pages, 2014. doi: $10.1155 / 2014 / 615958$

15. Oberoi JK, Wattal C, Goel N, Raveendran R, Datta S, Prasad K. Non-albicans Candida species in blood stream infections in a tertiary care hospital at New Delhi, India. The Indian Journal of Medical Research. 2012;136(6):997-1003.

16. Grlic ${ }^{\prime}$ A L, Missoni E M, Ivanc ` ica $\mathrm{S}^{\sim}$ karic et al. Candida utilis candidaemia in neonatal patients. Journal of Medical Microbiology. 2011;60:838-41.

17. Shivadasan J, Raksha, Prashanth S Urs. Candida utilis causing neonatal Candidemia - A case report and literature review. Apollo Medicine. 2016;13(1):55-8.

18. Xess I, Jain N, Hasan F, Mandal P, Banerjee U. Epidemiology of candidemia in a tertiary care centre of North India: 5-Year Study. Infection 2007;35:256-9.

19. Kothari A, Sagar V. Epidemiology of Candida Bloodstream Infections in a Tertiary Care Institute in India. Indian J Med Microbiol 2008;27:171-2.

20. Giri S, Kindo A J. A review of Candida species causing blood stream infection. Indian J Med Microbiol 2012;30:270-8

21. Pfaller MA, Diekema DJ. Epidemiology of invasive candidiasis: A persistent public health problem. Clin Microbiol Rev 2007;20:133-63.

22. Playford EG, Marriott D, Nguyen Q, Chen S, Ellis D, Slavin M, Sorrell TC. Candidemia in non-neutropenic critically ill patients: risk factors for non-albicans Candida spp. Crit Care Med. 2008;36:2034-39.

23. Shivaprakasha S, Radhakrishnan R. Karim PMS. Candida spp. Other than Candida albicans: A major cause of fungaemia in a tertiary care centre. Indian J. Med. Microbiol. 2007;25(4):405-7.

24. Akortha EE, Nwaugo VO, Chikwe NO: Antifungal resistance among Candida species from patients with genitourinary tract infection isolated in Benin City, Edo state, Nigeria. Afr J Microbiol Res. 2009;3(11):694-9. 
25. Yesudhason BL, Mohanram K. Candida tropicalis as a Predominant Isolate from Clinical Specimens and its Antifungal Susceptibility Pattern in a Tertiary Care Hospital in Southern India. Journal of Clinical and Diagnostic Research: JCDR. 2015;9(7):DC14-DC16.

doi:10.7860/JCDR/2015/13460.6208. 